ARTICLE

https://doi.org/10.1038/s41467-019-11109-9

\title{
Chiral phosphoric acid catalyzed aminative dearomatization of $\alpha$-naphthols/Michael addition sequence
}

\author{
Zi-Lei Xia ${ }^{1}$, Chao Zheng (1D ${ }^{1}$, Ren-Qi Xu \& Shu-Li You (1D ${ }^{1,2}$
}

Asymmetric dearomatization reactions have recently emerged as a powerful tool for the rapid build-up of the molecular complexity. Chiral three-dimensional polycyclic molecules bearing contiguous stereogenic centers can be synthesized from readily available planar aromatic feedstocks. Here we report that an intermolecular asymmetric dearomatization reaction of $\alpha$ naphthols bearing a tethered nucleophile at the C4 position of the naphthol ring is achieved by a chiral phosphoric acid. The reaction proceeds via a highly chemo- and regioselective aminative dearomatization/Michael addition sequence, affording a wide array of functionalized cyclic ketones in good yields (up to 93\%) with excellent enantioselectivity (up to >99\% ee). The catalyst loading can be reduced to $0.1 \mathrm{~mol} \%$. Preliminary mechanistic investigations identify that the enantioselectivity is established in the dearomatization step, while the Michael addition is the rate-limiting step. A working model accounting for the origin of the stereochemistry is proposed based on DFT calculations.

\footnotetext{
${ }^{1}$ State Key Laboratory of Organometallic Chemistry, Center for Excellence in Molecular Synthesis, Shanghai Institute of Organic Chemistry, University of Chinese Academy of Sciences, Chinese Academy of Sciences, 345 Lingling Lu, 200032 Shanghai, China. ${ }^{2}$ Collaborative Innovation Center of Chemical Science and Engineering, 300072 Tianjin, China. Correspondence and requests for materials should be addressed to C.Z. (email: zhengchao@sioc.ac.cn) or to S.-L.Y. (email: slyou@sioc.ac.cn)
} 
$\mathrm{T}$ he demands for effective assembly of diverse molecular scaffolds are continuously growing along with the development of organic chemistry. Among various kinds of strategies that aim to rapidly increase molecular complexity, catalytic asymmetric dearomatization (CADA) reactions ${ }^{1-12}$ have recently received considerable attention of the synthetic community. They are capable of significantly enriching the chemical space by converting readily available planar aromatic compounds to diverse three-dimensional molecules bearing spiro or fused polycyclic skeletons with multiple stereogenic centers including quaternary ones.

Naphthols serve as important aromatic feedstocks in organic chemistry. However, the asymmetric dearomatization reactions of naphthols are relatively less explored compared with those of other electron-rich arenes like indoles ${ }^{13-18}$. With the oxidation system consisting of a chiral hypervalent iodine reagent and $m$-CPBA as the terminal oxidant ${ }^{19-29}$, or transition-metal catalysts that are capable of promoting single electron oxidation ${ }^{30,31}$, $\alpha$ - or $\beta$-naphthols could react with intra- or intermolecular nucleophiles to yield chiral functionalized cyclic ketones. Notably, the asymmetric dearomatization reactions under non-oxidative conditions are rather limited within $\beta$-naphthols ${ }^{32-52}$, and the corresponding reactions of $\alpha$-naphthols are relatively rare. In 2015, Luan and coworkers reported an elegant Pd-catalyzed dynamic kinetic asymmetric transformation of 4-(2-bromoaryl)$\alpha$-naphthols with alkynes for the synthesis of chiral spirocyclic enones ${ }^{53}$. Sporadic examples of non-oxidative asymmetric dearomatization of $\alpha$-naphthols via organocatalytic chlorination ${ }^{37}$, annulation $^{54}$, Ir-catalyzed allylic alkylation ${ }^{38}$, or Pd-catalyzed cross coupling ${ }^{55-57}$ were disclosed. However, the dearomatization reactions in these examples generally relied on the pre-installation of an intramolecular electrophile (Fig. 1a). Notably, during the preparation of this manuscript, Shao and coworkers reported an intermolecular asymmetric allylic dearomatization reaction of $\alpha$-naphthols at the C2 position by a chiral phosphoric acid 58 . However, highly efficient asymmetric dearomatization reactions of $\alpha$-naphthols with intermolecular electrophiles still remain underdeveloped.

In 2017, we reported a Pd-catalyzed arylative dearomatization/ aza-Michael addition sequence between aryl bromide and $\alpha$ naphthols bearing a tethered nucleophile at the $\mathrm{C} 4$ position of the naphthol ring ${ }^{59}$. The exclusive chemo-, and regioselectivity
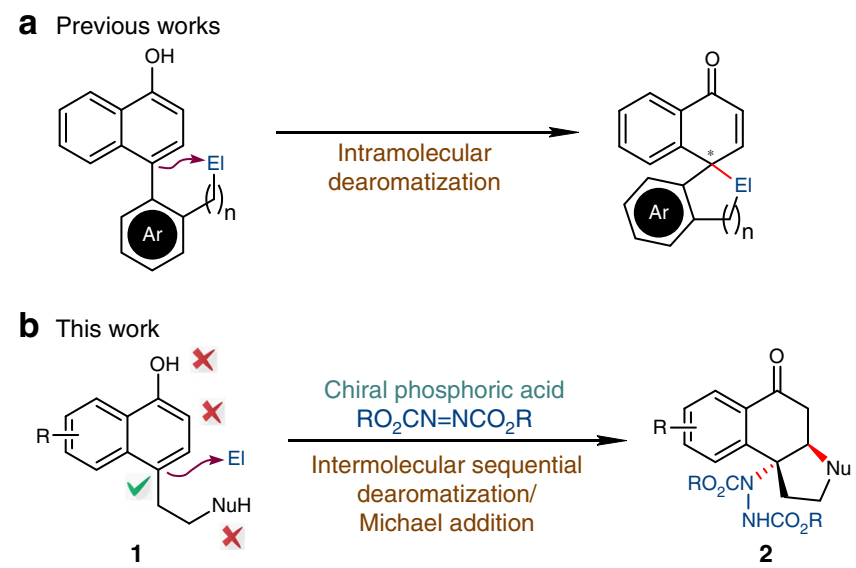

Exclusive chemo- and regioselectivity

Excellent diastereo- and enantioselectivity

Fig. 1 Catalytic Asymmetric Dearomatization of $\alpha$-Naphthols at the C4 Position. a Intramolecular dearomatization. $\mathbf{b}$ Intermolecular sequential dearomatization/Michael addition. Ar: aromatic ring, El: electrophile, Nu: nucleophile, R: substituent favoring the $\mathrm{C} 4$ position among the multiple potential nucleophilic sites encouraged us to further probe the possibility of developing a highly enantioselective dearomatization of $\alpha$-naphthols/Michael addition sequence. However, all attempts to realize such an asymmetric reaction under Pd catalysis have been failed in our hands. In this regard, we speculated that azodicarboxylates $^{60-66}$ might be employed as suitable electrophilic amination reagents which are compatible with the dearomatization of electron-rich arenes in the presence of a chiral phosphoric acid $(\mathrm{CPA})^{67-70}$.

Here, we accomplished the efficient synthesis of a wide array of functionalized cyclic ketones bearing two consecutive stereogenic centers in excellent diastereo- and enantioselectivity (Fig. 1b). The products are readily involved in further transformations towards various enantioenriched polycyclic molecules.

\section{Results}

Reaction development. Our studies commenced with the attempt of the reaction of $\alpha$-naphthol 1a with 1.5 equivalents of diethyl azodicarboxylate (DEAD) (Table 1). In the presence of $10 \mathrm{~mol} \%$ of chiral phosphoric acid $\mathbf{C l}$, the target reaction proceeded smoothly in 1,2-dichloroethane (DCE) at $50^{\circ} \mathrm{C}$ for $24 \mathrm{~h}$, affording the dearomatized product $\mathbf{2 a}$ in $85 \%$ yield with $75 \%$ ee as a single trans diastereoisomer (Table 1, entry 1). The structure and absolute configuration of $\mathbf{2 a}(3 R, 4 R)$ were established unambiguously by X-ray crystallographic analysis of an enantiopure sample. Interestingly, the Friedel-Crafts reaction at the C2 position was not observed. Systematic evaluation of a series of CPAs (C2-C7) was conducted (Table 1, entries 2-7). The results revealed that the catalysts have great influence on the reaction outcome. Notably, TRIP-CPA C2 gave the optimal results $(90 \%$ yield and $99 \%$ ee, Table 1, entry 2). Utilizing $\mathrm{SiPh}_{3}$-derived catalyst C4 also led to comparable results with those of C2 (90\% yield and $98 \%$ ee, Table 1, entry 4). On the other hand, $2 \mathbf{a}$ was obtained in the nearly racemic form $\left(2 \%\right.$ ee) when $4-\mathrm{NO}_{2} \mathrm{C}_{6} \mathrm{H}_{4}$ derived $\mathbf{C 6}$ was employed (Table 1, entry 6). Although excellent enantioselectivity has been obtained, other reaction parameters were further investigated. Typical solvents including EtOAc, THF or toluene also well facilitated the reaction (Table 1, entries 8-10). When the temperature was lowered to $40^{\circ} \mathrm{C}$, prolonged time $(36 \mathrm{~h})$ was necessary to provide $2 \mathrm{a}$ in $88 \%$ yield (Table 1, entry 11$)$. Similar results $(85 \%$ yield and $99 \%$ ee) could be achieved in shorter time when elevating the reaction temperature to $60^{\circ} \mathrm{C}$ (Table 1 , entry 12). However, slightly decreased yield $(77 \%)$ was observed when 1.1 equivalents of DEAD was used (Table 1, entry 13). The reactions proceeded well with reduced loading of $\mathbf{C 2}(\leq 1 \mathrm{~mol} \%$, Table 1 , entries 14-17). The remarkably high catalytic efficiency was exemplified by the fact that $\mathbf{2 a}$ was afforded in $52 \%$ yield with $97 \%$ ee in the presence of $0.1 \mathrm{~mol} \%$ of $\mathbf{C 2}$ at $80^{\circ} \mathrm{C}$ (Table 1, entry 17). However, only complex mixture was obtained in the absence of a CPA catalyst (Table 1, entry 18).

Scope and limitation. With the optimal conditions in hands (Table 1, entry 2), we next explored the substrate scope (Fig. 2). The desired reactions of 1a with other azodicarboxylates all proceeded smoothly, leading to $\mathbf{2 b}-\mathbf{2 d}$ in high yields (88-89\%). The $N$-protecting group of $\alpha$-naphthol substrates could be switched to $\mathrm{Ns}, \mathrm{CO}_{2} \mathrm{Me}$ or $p-\mathrm{MeC}_{6} \mathrm{H}_{4} \mathrm{CO}_{2}$. The corresponding products $(2 \mathbf{e}-\mathbf{2 g})$ could be obtained in $89-92 \%$ yields. The prolonged tether at the $\mathrm{C} 4$ position of the naphthol ring was well accommodated, affording the piperidine-fused product $\mathbf{2 h}$ in $93 \%$ yield. Besides nitrogen nucleophiles, the hydroxyl group could also work as the nucleophile. The tetrahydrofuran-fused product $\mathbf{2 i}$ was accomplished smoothly in $87 \%$ yield. Notably, when a malonate diester nucleophile was employed, only the dearomatization 


\section{Table 1 Optimization of the reaction conditions ${ }^{a}$}

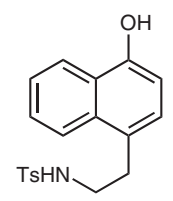

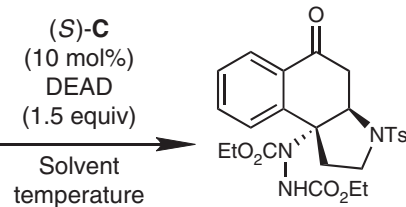

$2 \mathrm{a}$

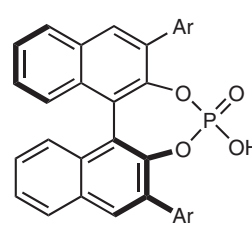

Ar $=9$-phenanthryl

C2, $\mathrm{Ar}=2,4,6-(\mathrm{Pr})_{3} \mathrm{C}_{6} \mathrm{H}_{2}$

C3, $\mathrm{Ar}=1$-naphthyl

$\mathrm{C} 4, \mathrm{Ar}=\mathrm{SiPh}_{3}$

C5, $\mathrm{Ar}=3,5-\left(\mathrm{CF}_{3}\right)_{2} \mathrm{C}_{6} \mathrm{H}_{3}$

C6, $\mathrm{Ar}=4-\mathrm{NO}_{2} \mathrm{C}_{6} \mathrm{H}_{4}$

C7, Ar = 9-anthryl

\begin{tabular}{|c|c|c|c|c|c|c|}
\hline Entry & C & Solvent & Temperature $\left({ }^{\circ} \mathrm{C}\right)$ & Time (h) & Yield $(\%)^{\mathbf{b}}$ & ee $(\%)^{c}$ \\
\hline 1 & C1 & DCE & 50 & 24 & 85 & 75 \\
\hline 2 & C2 & DCE & 50 & 24 & 90 & 99 \\
\hline 3 & C3 & DCE & 50 & 24 & 87 & 63 \\
\hline 4 & C4 & DCE & 50 & 24 & 90 & 98 \\
\hline 5 & C5 & DCE & 50 & 24 & 85 & 57 \\
\hline 6 & C6 & DCE & 50 & 24 & 83 & 2 \\
\hline 7 & C7 & DCE & 50 & 24 & 83 & 59 \\
\hline 8 & C2 & EtOAc & 50 & 24 & 86 & 97 \\
\hline 9 & C2 & $\mathrm{THF}$ & 50 & 24 & 85 & 96 \\
\hline 10 & C2 & toluene & 50 & 24 & 87 & 98 \\
\hline 11 & C2 & DCE & 40 & 36 & 88 & 99 \\
\hline 12 & C2 & DCE & 60 & 12 & 85 & 99 \\
\hline $13^{d}$ & $\mathrm{C2}$ & DCE & 50 & 36 & 77 & 99 \\
\hline $14^{\mathrm{e}}$ & $\mathrm{C} 2$ & DCE & 50 & 96 & 81 & 99 \\
\hline $15^{e}$ & C2 & DCE & 80 & 30 & 81 & 99 \\
\hline $16^{f}$ & C2 & DCE & 80 & 24 & 69 & 98 \\
\hline $17 \mathrm{~g}$ & C2 & DCE & 80 & 24 & 52 & 97 \\
\hline 18 & / & DCE & 50 & 12 & complex & N.D. \\
\hline
\end{tabular}

DEAD diethyl azodicarboxylate, Ts tosyl, Et ethyl, iPr isopropyl, Ph phenyl, DCE 1,2-dichloroethane, EtOAc ethyl acetate, THF tetrahydrofuran, N.D. not determined

Reaction conditions: 1a $(0.1 \mathrm{mmol})$, DEAD $(0.15 \mathrm{mmol})$ and $\mathbf{C}(10 \mathrm{~mol} \%)$ in solvent $(2.0 \mathrm{~mL})$ at specified temperature

blsolated yield

'Determined by HPLC analysis on a chiral stationary phase

dDEAD (1.1 equiv) was used

e'2 (1 mol\%) was used

C2 $(0.2 \mathrm{~mol} \%)$ was used

${ }^{\mathrm{C}} \mathbf{C} 2(0.1 \mathrm{~mol} \%)$ was used

process occurred under the standard conditions. The target product $2 \mathbf{j}$ could be obtained (81\% yield) after a subsequent Michael addition promoted by ${ }^{t} \mathrm{BuOK}$.

On the other hand, various substituted $\alpha$-naphthols underwent the desired dearomatization reactions. Electron-donating groups such as $\mathrm{MeO}$ and Me could be tolerated at the $\mathrm{C} 6$ to $\mathrm{C} 8$ positions (2k-2p, 91-93\% yields). The C6 and C7 positions could accommodate halogen atoms including $\mathrm{Cl}$ and $\mathrm{Br}$ (2q-2s, $90-93 \%$ yields). Besides, when a $\mathrm{CN}$ group was installed at the C6 or C7 position, the dearomatization reaction delivered the desired products in high yields (2t, $93 \%$ yield; $2 \mathbf{u}, 91 \%$ yield). Gratifyingly, exceedingly high enantioselectivity was observed in all the above cases (2a-2u, 98 to $>99 \%$ ee). However, when the substrate bearing a methyl group at the $\mathrm{C} 2$ position was subjected to the standard conditions, the reaction outcomes decreased apparently in terms of yield and enantioselectivity (2v, 34\% yield and $78 \%$ ee). It should be noted that only complex mixtures were obtained when substrates bearing a substituent at the C5 position were utilized.

The dearomatization reaction of phenols is much more challenging compared with that of naphthols. In addition, byproducts of Friedel-Crafts reactions are difficult to be avoided. To further expand the substrate scope of this aminative dearomatization/Michael addition sequence, several phenol analogs were tested (Fig. 3). Encouragingly, $\alpha$-tetrahydronaphthol-derived substrate 3a participated the title reaction smoothly, delivering the desired product $4 \mathbf{a}$ in $90 \%$ yield with $96 \%$ ee, without the observation of Friedel-Crafts by-product. The reaction of sterically less demanding phenol substrate $\left(2,3-\mathrm{Me}_{2}\right)$ also proceeded well. The corresponding product $\mathbf{4 b}$ was obtained in good yield $(82 \%)$ but with rather decreased enantioselectivity (53\% ee). Notably, a mixture of Friedel-Crafts-type byproducts became dominating for the substrates bearing one substituent ( $\mathrm{Me}, \mathrm{MeO}$, or $\mathrm{Br}$ ) at the $\mathrm{C} 2$ or $\mathrm{C} 3$ position. Compound 5 was isolated in $84 \%$ yield for the phenol substrate bearing no substituent at the $\mathrm{C} 2$ or $\mathrm{C} 3$ position.

Mechanistic studies. To shed light on the reaction mechanism, we first attempted to isolate the intermediate of this sequential reaction (Fig. 4). When the reaction of 1 a was quenched within 30 min, only trace amount of 2 a was observed ( $<5 \%$ NMR yield), while conjugated enone 6 was isolated in $86 \%$ yield with $>99 \%$ ee. Compound 6 was found stable enough to be stored at $-20^{\circ} \mathrm{C}$ for weeks without apparent transformation into $\mathbf{2 a}$ or decomposition. Taking into consideration that much longer time $(24 \mathrm{~h})$ was required for most substrates to fully transfer into the final products, and the identical enantiopurity of $\mathbf{6}$ and that of $\mathbf{2 a}$ obtained under the standard conditions, we proposed that the stereochemistry of the whole reaction is established irreversibly in the aminative dearomatization step, whereas the following Michael addition is the rate-limiting step.

To explore the origin of the exceedingly high enantioselectivity, DFT calculations were then performed for the aminative dearomatization step (Fig. 5). The relative Gibbs free energy of TS-major, the transition state leading to the major product, was $2.0 \mathrm{kcal} / \mathrm{mol}$ lower than that of TS-minor, which was in qualitative agreement with the experimental results. The two 
<smiles></smiles>

1

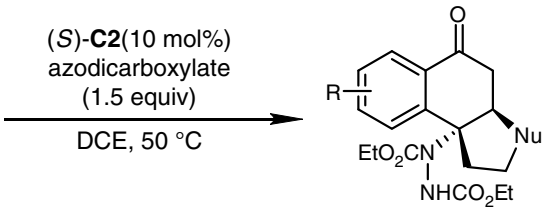

2

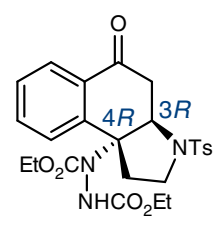

2a

$90 \%$ yield, $99 \%$ ee<smiles>CCOC(=O)N[C@]12CCN(C(C)=O)[C@@H]1CC(=O)c1ccccc12</smiles>

$2 f$

$90 \%$ yield, $99 \%$ ee

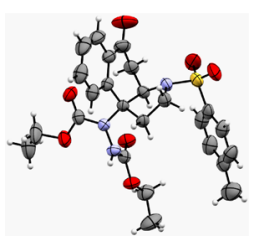

X-Ray of $2 a$

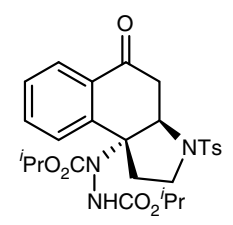

2b

$89 \%$ yield, $>99 \%$ ee

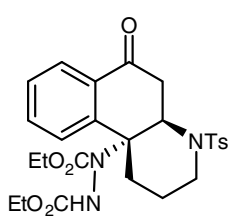

2h

93\% yield, $98 \%$ ee

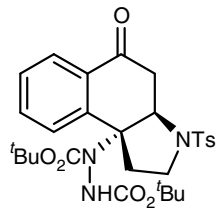

2c

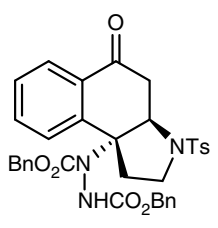

2d

$89 \%$ yield, $>99 \%$ ee<smiles>CCC[NH+](NC(=O)OCC)[C@@]12CCC(C(C)=O)(C(C)=O)[C@H]1CC(=O)c1ccccc12</smiles>

$\mathbf{2 j}^{a}$<smiles>CCOCN[N+](=O)[C@]12CC[NH+]([SH+])[C@H]1CC(=O)c1cc(OC)ccc12</smiles>

2 I

$91 \%$ yield, $>99 \%$ ee<smiles>CCOC(=O)NN[N+]1([S-])CC[C@@]2(c3ccccc3)c3ccc(Br)cc3C(=O)C[C@H]21</smiles>

$2 r$

$90 \%$ yield, $>99 \%$ ee

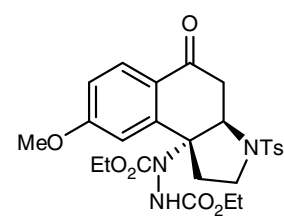

$2 \mathrm{~m}$

91\% yield, $99 \%$ ee

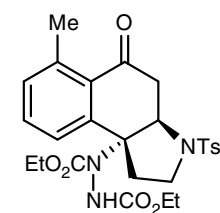

2n $2 i$<smiles>CCOCN[NH+](OCC)[C@@]12CCO[C@H]1CC(=O)c1ccccc12</smiles>

$87 \%$ yield, $>99 \%$ ee

$81 \%$ yield, $99 \%$ ee

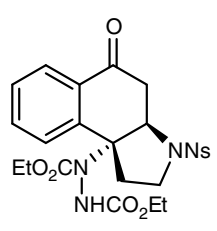

$2 e$

$89 \%$ yield, $98 \%$ ee

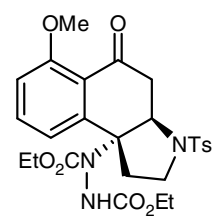

2k

$91 \%$ yield, $98 \%$ ee

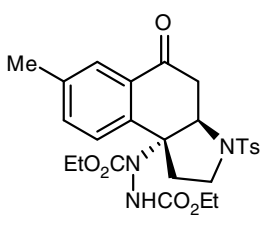

20

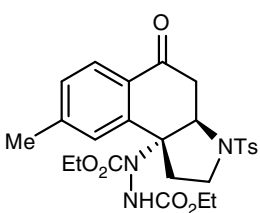

$2 p$

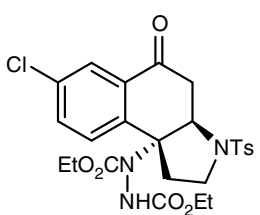

$2 q$<smiles></smiles>

$2 s$

$92 \%$ yield, $98 \%$ ee

$92 \%$ yield, $99 \%$ ee

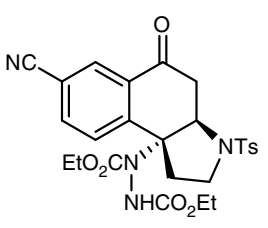

$2 t$
93\% yield, >99\% ee

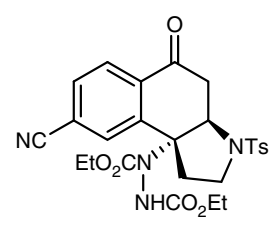

$2 \mathbf{u}$
$93 \%$ yield, $>99 \%$ ee

$92 \%$ yield, $98 \%$ ee

$93 \%$ yield, $>99 \%$ ee

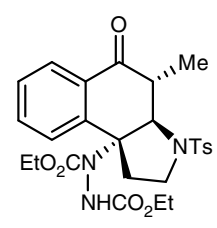

$\mathbf{2} \mathbf{v}^{b}$

$34 \%$ yield, $78 \%$ ee

Fig. 2 Substrate Scope of $\alpha$-Naphthols. Reaction conditions: $1(0.1 \mathrm{mmol})$, azodicarboxylate $(0.15 \mathrm{mmol})$ and $(\mathrm{S})$-C2 (10 mol\%) in DCE (2 mL) at $50{ }^{\circ} \mathrm{C}$.

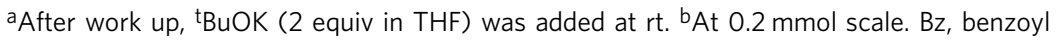

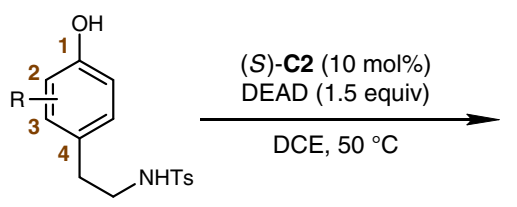

3<smiles>CCOC(=O)N[C@]12CCCC1=C1CCCC[N+]1(CC)CC2</smiles>

$4 a$

$90 \%$ yield, $96 \%$ ee

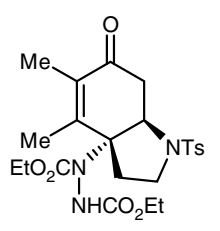

$4 b$
$82 \%$ yield, $53 \%$ ee

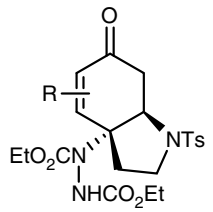

4<smiles>CCOC(=O)NN(C(=O)OCC)c1cc(CCN[Sb])ccc1O</smiles>

5

$84 \%$ yield

Fig. 3 Substrate Scope of Phenols. Reaction conditions: 3 ( $0.1 \mathrm{mmol})$, $\operatorname{DEAD}(0.15 \mathrm{mmol})$ and $(\mathrm{S})-\mathbf{C 2}(10 \mathrm{~mol} \%)$ in DCE $(2 \mathrm{~mL})$ at $50^{\circ} \mathrm{C}$. Me, methyl

prochiral faces at the $\mathrm{C} 4$ position of $\alpha$-naphthol were well discriminated by the chiral phosphoric acid. In TS-major, the Siface of the $\mathrm{C} 4$ position was attacked, which allowed the intact benzene ring of $\alpha$-naphthol in distal to the chiral pocket. Whereas in TS-minor, strong steric congestion was developed due to the $R e$-face attack and the concomitant approximation of the intact benzene ring to one TRIP group of $\mathbf{C 2}$. These computational results corresponded well with the fact that substituents were tolerated at the C6 to C8 positions of $\alpha$-naphthol ( $2 \mathbf{k}-\mathbf{2 u})$, but not at the $\mathrm{C} 2$ position (2v). In addition, a fused saturated skeleton that is sterically roughly comparable with a benzene ring should be beneficial for the high enantioselectivity (4a), but sterically less demanding 2,3- $\mathrm{Me}_{2}$ groups were not that effective (4b).

Product transformations. To highlight the practicality and synthetic utility of this method, a gram-scale reaction of 1a with DEAD was performed under the standard reaction conditions. 2a was obtained in $87 \%$ yield ( $1.35 \mathrm{~g}$ ) with $99 \%$ ee. In addition, several functional group transformations of $\mathbf{2 a}$ were demonstrated (Fig. 6). Tertiary alcohol 7 was delivered in $91 \%$ yield 


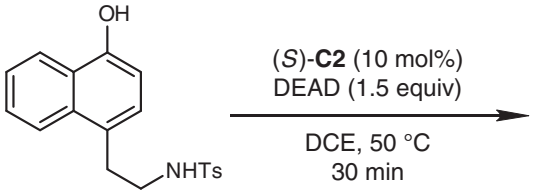

1a<smiles>CCOC(=O)N[C@@]1(CCN[SnH3])C=CC(=O)c2ccccc21</smiles>

$86 \%$ yield, $>99 \%$ ee

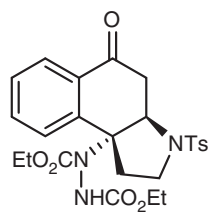

$2 a$

Fig. 4 Isolation of the Intermediate. Reaction conditions: 1a (0.1 mmol), DEAD (0.15 mmol) and (S)-C2 (10 mol\%) in DCE (2 mL) at $50{ }^{\circ} \mathrm{C}$ for $30 \mathrm{~min}$

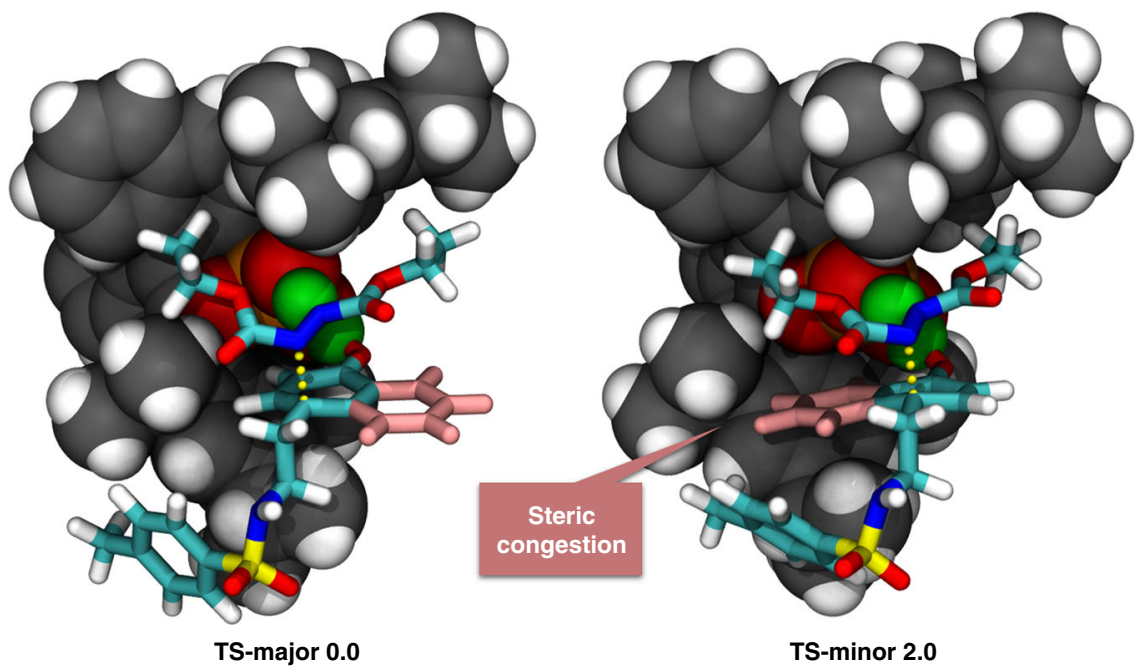

Fig. 5 Transition states. Optimized structures and relative Gibbs free energies (in $\mathrm{kcal} / \mathrm{mol}$ ) of the transition states of the aminative dearomatization step $\left(\omega \mathrm{B} 97 \mathrm{XD} / \mathrm{def2}-\mathrm{TZVPP} / / \mathrm{B} 97 \mathrm{D} / 6-31 \mathrm{G}^{\star \star}\right)$. The catalysts are presented with the van der Waals model. The substrates are presented with the stick model. The forming $\mathrm{C}-\mathrm{C}$ bonds are shown in yellow dash lines. The transferring protons are shown in green spheres. The intact benzene rings of $\alpha$-naphthols are shown in pink
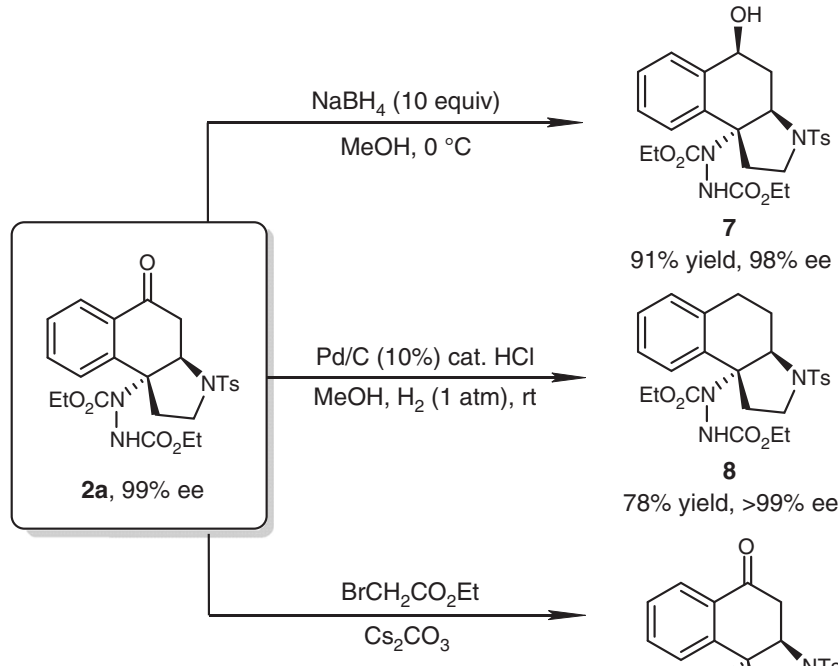

$91 \%$ yield, $98 \%$ ee

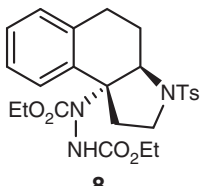

$78 \%$ yield, $>99 \%$ ee

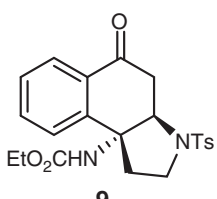

$52 \%$ yield, $98 \%$ ee

Fig. 6 Transformations of $\mathbf{2 a}$. Reaction conditions for synthesis of 7: $\mathbf{2 a}(0.2$ $\mathrm{mmol}), \mathrm{NaBH}_{4}(2.0 \mathrm{mmol})$ in $\mathrm{MeOH}(4 \mathrm{~mL})$ at $0^{\circ} \mathrm{C}$. Reaction conditions for synthesis of $\mathbf{8}: \mathbf{2 a}(0.2 \mathrm{mmol}), \mathrm{Pd} / \mathrm{C}(10 \%, 50 \mathrm{mg}), \mathrm{HCl}$ (conc. $20 \mu \mathrm{L})$ in $\mathrm{MeOH}(4 \mathrm{~mL})$ under $\mathrm{H}_{2}(1 \mathrm{~atm})$ at room temperature. Reaction conditions for synthesis of 9: $\mathbf{2 a}(0.2 \mathrm{mmol}), \mathrm{Cs}_{2} \mathrm{CO}_{3}(0.26 \mathrm{mmol}), \mathrm{BrCH}_{2} \mathrm{CO}_{2} \mathrm{Et}(0.22 \mathrm{mmol})$ in $\mathrm{CH}_{3} \mathrm{CN}(4 \mathrm{~mL})$ at $50^{\circ} \mathrm{C}$

when treated with $\mathrm{NaBH}_{4}$. The ketone group could also be hydrogenated to methylene group under the catalysis of palladium on charcoal, leading to $\mathbf{8}$ in $78 \%$ yield. In addition, the $\mathrm{N}-\mathrm{N}$ bond could be cleaved by treating $2 \mathbf{a}$ with ethyl bromoacetate and cesium carbonate. The corresponding product 9 was afforded in $52 \%$ yield. Notably, no erosion of enantiomeric purity was observed in all these transformations.

\section{Discussion}

In conclusion, we have achieved a chiral phosphoric acidcatalyzed dearomatization reaction of $\alpha$-naphthols bearing a tethered nucleophile at the $\mathrm{C} 4$ position of the naphthol ring. Preliminary mechanistic investigations confirmed that the reaction proceeded via two steps, a stereochemistry-determining aminative dearomatization followed by a rate-limiting Michael addition. The reaction occurred under mild conditions, affording a wide array of polycyclic ketones in good yields with excellent enantioselectivity. Besides, the reaction features high catalytic efficiency and diverse transformations of the products. A working model accounting for the origin of the stereochemical induction was proposed based on DFT calculations.

\section{Methods}

Representative procedure. To a flask containing a mixture of $1 \mathbf{1 a}(0.1 \mathrm{mmol})$ and (S)-C2 $(7.5 \mathrm{mg}, 0.01 \mathrm{mmol})$ under argon was added a solution of the corresponding azodicarboxylate $(0.15 \mathrm{mmol})$ in anhydrous 1,2 -dichloroethane $(2 \mathrm{~mL})$. The reaction was stirred at $50{ }^{\circ} \mathrm{C}$ until TLC showed complete consumption of the starting material. The reaction mixture was cooled to room temperature, quenched with $\mathrm{NaHCO}_{3}$ (aq., $10 \mathrm{~mL})$ and extracted with $\mathrm{CH}_{2} \mathrm{Cl}_{2}(3 \times 15 \mathrm{~mL})$. The combined organic layer was washed with brine, separated, dried over $\mathrm{Na}_{2} \mathrm{SO}_{4}$ and filtrated. After the solvent was 
removed under reduced pressure, the residue was purified by silica gel column chromatography (ethyl acetate/petroleum ether $=1 / 6$ to $1 / 2$ ) to afford $2 \mathbf{a}$.

\section{Data availability}

The X-ray crystallographic coordinates for product 2a have been deposited at the Cambridge Crystallographic Data Centre (CCDC) with the accession code 1888563. These data can be obtained free of charge from The Cambridge Crystallographic Data Centre via www.ccdc.cam.ac.uk/data_request/cif. The authors declare that all other data supporting the findings of this work, including experimental procedures, compound characterization data, and computational details, are available within the article and its Supplementary Information files.

Received: 25 March 2019 Accepted: 11 June 2019

Published online: 17 July 2019

\section{References}

1. Pape, A. R., Kaliappan, K. P. \& Kündig, E. P. Transition-metal-mediated dearomatization reactions. Chem. Rev. 100, 2917-2940 (2000).

2. Roche, S. P. \& Porco, J. A. Jr. Dearomatization strategies in the synthesis of complex natural products. Angew. Chem. Int. Ed. 50, 4068-4093 (2011).

3. Zhuo, C.-X., Zhang, W. \& You, S.-L. Catalytic asymmetric dearomatization reactions. Angew. Chem. Int. Ed. 51, 12662-12686 (2012).

4. Zhuo, C.-X., Zheng, C. \& You, S.-L. Transition-metal-catalyzed asymmetric allylic dearomatization reactions. Acc. Chem. Res. 47, 2558-2573 (2014).

5. Ding, Q., Zhou, X. \& Fan, R. Recent advances in dearomatization of heteroaromatic compounds. Org. Biomol. Chem. 12, 4807-4815 (2014).

6. Zheng, C. \& You, S.-L. Catalytic asymmetric dearomatization by transitionmetal catalysis: a method for transformations of aromatic compounds. Chem 1, 830-857 (2016).

7. Manoni, E., De Nisi, A. \& Bandini, M. New opportunities in the stereoselective dearomatization of indoles. Pure Appl. Chem. 88, 207-214 (2016).

8. Chen, J.-B. \& Jia, Y.-X. Recent progress in transition-metal-catalyzed enantioselective indole functionalizations. Org. Biomol. Chem. 15, 3550-3567 (2017).

9. Wu, W.-T., Zhang, L. \& You, S.-L. Recent progress on gold-catalyzed dearomatization reactions. Acta Chim. Sin. 75, 419-438 (2017)

10. Wertjes, W. C., Southgate, E. H. \& Sarlah, D. Recent advances in chemical dearomatization of nonactivated arenes. Chem. Soc. Rev. 47, 7996-8017 (2018).

11. An, J. \& Bandini, M. Gold-catalyzed dearomatization reactions. Chimia 72, 610-613 (2018).

12. You, S.-L. Ed. Asymmetric Dearomatization Reactions (Wiley-VCH, Weinheim, Germany, 2016).

13. Quideau, S., Pouységu, L. \& Deffieux, D. Oxidative dearomatization of phenols: why, how and what for? Synlett 467-495 (2008).

14. Pouységu, L., Deffieux, D. \& Quideau, S. Hypervalent iodine-mediated phenol dearomatization in natural product synthesis. Tetrahedron 66, 2235-2261 (2010).

15. Pouységu, L. et al. Hypervalent iodine-mediated oxygenative phenol dearomatization reactions. Tetrahedron 66, 5908-5917 (2010).

16. Wu, W.-T., Zhang, L. \& You, S.-L. Catalytic asymmetric dearomatization (CADA) reactions of phenol and aniline derivatives. Chem. Soc. Rev. 45, 1570-1580 (2016).

17. Sun, W., Li, G., Hong, L. \& Wang, R. Asymmetric dearomatization of phenols. Org. Biomol. Chem. 14, 2164-2176 (2016).

18. Flores, A., Cots, E., Bergès, J. \& Muñiz, K. Enantioselective iodine(I/III) catalysis in organic synthesis. Adv. Synth. Catal. 361, 2-25 (2019).

19. Dohi, T. et al. A chiral hypervalent iodine(III) reagent for enantioselective dearomatization of phenols. Angew. Chem. Int. Ed. 47, 3787-3790 (2008)

20. Quideau, S. et al. Asymmetric hydroxylative phenol dearomatization through in situ generation of iodanes from chiral iodoarenes and $m$-СРBA. Angew. Chem. Int. Ed. 48, 4605-4609 (2009).

21. Uyanik, M., Yasui, T. \& Ishihara, K. Enantioselective Kita oxidative spirolactonization catalyzed by in situ generated chiral hypervalent iodine(III) species. Angew. Chem. Int. Ed. 49, 2175-2177 (2010)

22. Dohi, T. et al. Asymmetric dearomatizing spirolactonization of naphthols catalyzed by spirobiindane-based chiral hypervalent iodine species. J. Am. Chem. Soc. 135, 4558-4566 (2013).

23. Uyanik, M., Yasui, T. \& Ishihara, K. Hydrogen bonding and alcohol effects in asymmetric hypervalent iodine catalysis: enantioselective oxidative dearomatization of phenols. Angew. Chem. Int. Ed. 52, 9215-9218 (2013)

24. Volp, K. A. \& Harned, A. M. Chiral aryl iodide catalysts for the enantioselective synthesis of para-quinols. Chem. Commun. 49, 3001-3003 (2013).
25. Bosset, C. et al. Asymmetric hydroxylative phenol dearomatization promoted by chiral binaphthylic and biphenylic iodanes. Angew. Chem. Int. Ed. 53, 9860-9864 (2014).

26. Murray, S. J. \& Ibrahim, H. Asymmetric Kita spirolactonisation catalysed by anti-dimethanoanthracene-based iodoarenes. Chem. Commun. 51, 2376-2379 (2015).

27. Zhang, D.-Y., Xu, L., Wu, H. \& Gong, L.-Z. Chiral iodine-catalyzed dearomatizative spirocyclization for the enantioselective construction of an all-carbon stereogenic center. Chem. Eur. J. 21, 10314-10317 (2015).

28. Uyanik, M., Yasui, T. \& Ishihara, K. Chiral hypervalent organoiodinecatalyzed enantioselective oxidative spirolactonization of naphthol derivatives. J. Org. Chem. 82, 11946-11953 (2017).

29. Hempel, C., Maichle-Mössmer, C., Pericàs, M. A. \& Nachtsheim, B. J. Modular synthesis of triazole-based chiral iodoarenes for enantioselective spirocyclizations. Adv. Synth. Catal. 359, 2931-2941 (2018).

30. Oguma, T. \& Katsuki, T. Iron-catalyzed dioxygen-driven C-C bond formation: oxidative dearomatization of 2-naphthols with construction of a chiral quaternary stereocenter. J. Am. Chem. Soc. 134, 20017-20020 (2012).

31. Oguma, T. \& Katsuki, T. Iron-catalysed asymmetric tandem spiro-cyclization using dioxygen in air as the hydrogen acceptor. Chem. Commun. 50, 5053-5056 (2014).

32. Zhuo, C.-X. \& You, S.-L. Palladium-catalyzed intermolecular asymmetric allylic dearomatization reaction of naphthol derivatives. Angew. Chem. Int. Ed. 52, 10056-10059 (2013)

33. Zheng, J., Wang, S.-B., Zheng, C. \& You, S.-L. Asymmetric dearomatization of naphthols via a $\mathrm{Rh}$-catalyzed $\mathrm{C}\left(\mathrm{sp}^{2}\right)-\mathrm{H}$ functionalization/annulation reaction. J. Am. Chem. Soc. 137, 4880-4883 (2015).

34. Yang, D. et al. Intermolecular enantioselective dearomatization reaction of $\beta$ naphthol using meso-aziridine: a bifunctional in situ generated magnesium catalyst. Angew. Chem. Int. Ed. 54, 2185-2189 (2015).

35. Yang, $\mathrm{D}$. et al. Application of a $\mathrm{C}-\mathrm{C}$ bond-forming conjugate addition reaction in asymmetric dearomatization of $\beta$-naphthols. Angew. Chem. Int. Ed. 54, 9523-9527 (2015).

36. Wang, S.-G. et al. Asymmetric dearomatization of $\beta$-naphthols through a bifunctional-thiourea-catalyzed Michael reaction. Angew. Chem. Int. Ed. 54 14929-14932 (2015)

37. Yin, Q. et al. Organocatalytic asymmetric chlorinative dearomatization of naphthols. Chem. Sci. 6, 4179-4183 (2015).

38. Cheng, Q., Wang, Y. \& You, S.-L. Chemo-, diastereo-, and enantioselective iridium-catalyzed allylic intramolecular dearomatization reaction of naphthol derivatives. Angew. Chem. Int. Ed. 55, 3496-3499 (2016).

39. Wang, L. et al. MgII-mediated catalytic asymmetric dearomatization (CADA) reaction of $\beta$-naphthols with dialkyl acetylenedicarboxylates. Chem. Eur. J. 22, 8483-8487 (2016)

40. Zhu, G. et al. Chiral phosphoric acid catalyzed asymmetric oxidative dearomatization of naphthols with quinones. Org. Lett. 18, 5288-5291 (2016)

41. Tu, H.-F., Zheng, C., Xu, R.-Q., Liu, X.-J. \& You, S.-L. Iridium-catalyzed intermolecular asymmetric dearomatization of $\beta$-naphthols with allyl alcohols or allyl ethers. Angew. Chem. Int. Ed. 56, 3237-3241 (2017).

42. Shen, D., Chen, Q., Yan, P., Zeng, X. \& Zhong, G. Enantioselective dearomatization of naphthol derivatives with allylic alcohols by cooperative iridium and Brønsted acid catalysis. Angew. Chem. Int. Ed. 56, 3242-3246 (2017).

43. Zhang, Y. et al. Catalytic asymmetric hydroxylative dearomatization of 2naphthols: synthesis of lacinilene derivatives. Chem. Sci. 8, 6645-6649 (2017).

44. Ge, S. et al. Chiral $\mathrm{N}, \mathrm{N}^{\prime}$-dioxide/ $\mathrm{Sc}(\mathrm{OTf})_{3}$ complex-catalyzed asymmetric dearomatization of $\beta$-naphthols. Chem. Commun. 53, 11759-11762 (2017).

45. Li, X.-Q. et al. Asymmetric arylative dearomatization of $\beta$-naphthols catalyzed by a chiral phosphoric acid. Chem. Eur. J. 23, 5381-5385 (2017).

46. An, J. et al. Gold-catalyzed dearomatization of 2-naphthols with alkynes. Chem. Eur. J. 23, 17473-17477 (2017)

47. Liu, X. et al. Construction of vicinal all-carbon quaternary stereocenters enabled by a catalytic asymmetric dearomatization reaction of $\beta$-naphthols with 3-bromooxindoles. ACS Catal. 8, 10888-10894 (2018).

48. Wang, P. et al. Asymmetric dearomative halogenation of $\beta$-naphthols: the axial chirality transfer reaction. Adv. Synth. Catal. 360, 401-405 (2018).

49. Wang, Y.-F. et al. Asymmetric brominative dearomatization of naphthols catalyzed by chiral copper complexes. Adv. Synth. Catal. 360, 2285-2290 (2018).

50. Wang, L. et al. Diversiform reactivity of naphthols in asymmetric dearomatization or O-alkylation reactions with aziridines. Adv. Synth. Catal. 360, 4491-4496 (2018).

51. Han, L., Wang, H. \& Luan, X. Pd(II)-Catalyzed [3+2] spiroannulation of $\alpha-$ aryl- $\beta$-naphthols with alkynes via a $\mathrm{C}-\mathrm{H}$ activation/dearomatization approach. Org. Chem. Front 5, 2453-2457 (2018).

52. Wang, J.-J., Yang, H., Gou, B.-B., Zhou, L. \& Chen, J. Enantioselective organocatalytic sulfenylation of $\beta$-naphthols. J. Org. Chem. 83, 4730-4738 (2018). 
53. Yang, L. et al. Palladium-catalyzed dynamic kinetic asymmetric transformation of racemic biaryls: axial-to-central chirality transfer. J. Am. Chem. Soc. 137, 4876-4879 (2015).

54. Zhu, G. et al. Catalytic kinetic resolution of spiro-epoxyoxindoles with 1naphthols: switchable asymmetric tandem dearomatization/oxa-Michael reaction and Friedel-Crafts alkylation of 1-naphthols at the C4 position. ACS Catal. 8, 1810-1816 (2018).

55. Rousseaux, S., García-Fortanet, J., Del Aguila Sanchez, M. A. \& Buchwald, S. L. Palladium(0)-catalyzed arylative dearomatization of phenols. J. Am. Chem. Soc. 133, 9282-9285 (2011).

56. Bai, L. et al. Palladium(0)-catalyzed intermolecular carbocyclization of $(1, n)$ diynes and bromophenols: an efficient route to tricyclic scaffolds. Angew. Chem. Int. Ed. 55, 6946-6950 (2016).

57. Zhao, G., Xu, G., Qian, C. \& Tang, W. Efficient enantioselective syntheses of (+)-dalesconol A and B. J. Am. Chem. Soc. 139, 3360-3363 (2017).

58. Yang, B. et al. Organocatalyzed intermolecular asymmetric allylic dearomatization of both $\alpha$ - and $\beta$-naphthols. Org. Lett. 21, 330-334 (2019).

59. Xu, R.-Q., Gu, Q. \& You, S.-L. Construction of the benzomesembrine skeleton: palladium(0)-catalyzed intermolecular arylative dearomatization of $\alpha$ naphthols and subsequent aza-Michael reaction. Angew. Chem. Int. Ed. 56, 7252-7256 (2017).

60. List, B. Direct catalytic asymmetric $\alpha$-amination of aldehydes. J. Am. Chem Soc. 124, 5656-5657 (2002).

61. Brandes, S., Bella, M., Kjærsgaard, A. \& Jørgensen, K. A. Chirally aminated 2naphthols-organocatalytic synthesis of non-biaryl atropisomers by asymmetric Friedel-Crafts amination. Angew. Chem. Int. Ed. 45, 1147-1151 (2006).

62. Matsubara, R. \& Kobayashi, S. Catalytic asymmetric amination of enecarbamates. Angew. Chem. Int. Ed. 45, 7993-7995 (2006).

63. Zhang, Z. \& Antilla, J. C. Enantioselective construction of pyrroloindolines catalyzed by chiral phosphoric acids: total synthesis of

(-)-debromoflustramine B. Angew. Chem. Int. Ed. 51, 11778-11782 (2012).

64. Wang, S.-G., Yin, Q., Zhuo, C.-X. \& You, S.-L. Asymmetric dearomatization of $\beta$-naphthols through an amination reaction catalyzed by a chiral phosphoric acid. Angew. Chem. Int. Ed. 54, 647-650 (2015).

65. Nan, J. et al. Direct asymmetric dearomatization of 2-naphthols by scandiumcatalyzed electrophilic amination. Angew. Chem. Int. Ed. 54, 2356-2360 (2015).

66. Lian, X., Lin, L., Wang, G., Liu, X. \& Feng, X. Chiral N,N'-dioxide-scandium (III)-catalyzed asymmetric dearomatization of 2-naphthols through an amination reaction. Chem. Eur. J. 21, 17453-17458 (2015).

67. Akiyama, T. Stronger Brønsted Acids. Chem. Rev. 107, 5744-5758 (2007).

68. Terada, M. Binaphthol-derived phosphoric acid as a versatile catalyst for enantioselective carbon-carbon bond forming reactions. Chem. Commun. 4097-4112 (2008).

69. Yu, J., Shi, F. \& Gong, L.-Z. Brønsted-acid-catalyzed asymmetric multicomponent reactions for the facile synthesis of highly enantioenriched structurally diverse nitrogenous heterocycles. Acc. Chem. Res. 44, 1156-1171 (2011).

70. Parmar, D., Sugiono, E., Raja, S. \& Rueping, M. Complete field guide to asymmetric BINOL-phosphate derived Brønsted acid and metal catalysis: history and classification by mode of activation; Brønsted acidity, hydrogen bonding, ion pairing, and metal phosphates. Chem. Rev. 114, 9047-9153 (2014).

\section{Acknowledgements}

We thank Ministry of Science and Technology of China (2016YFA0202900), National Natural Science Foundation of China $(21772219,21821002)$, Science and Technology Commission of Shanghai Municipality (16XD1404300, 18QA1404900, 16490712200), Chinese Academy of Sciences (XDB20000000, QYZDYSSWSLH012) and the Youth Innovation Promotion Association (2017302) of CAS for generous financial support.

\section{Author contributions}

Z.-L.X. and R.-Q.X. initially discovered the title reaction. Z.-L.X. conducted the reaction development. Z.-L.X. and C.Z. performed the mechanistic studies. Z.-L.X., C.Z. and S.-L.Y. drafted and revised the manuscript. S.-L.Y. directed the whole project.

\section{Additional information}

Supplementary Information accompanies this paper at https://doi.org/10.1038/s41467 019-11109-9.

Competing interests: The authors declare no competing interests.

Reprints and permission information is available online at http://npg.nature.com/ reprintsandpermissions/

Peer review information: Nature Communications thanks Xiaoming Feng and other anonymous reviewer(s) for their contribution to the peer review of this work.

Publisher's note: Springer Nature remains neutral with regard to jurisdictional claims in published maps and institutional affiliations.

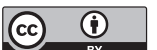

Open Access This article is licensed under a Creative Commons Attribution 4.0 International License, which permits use, sharing, adaptation, distribution and reproduction in any medium or format, as long as you give appropriate credit to the original author(s) and the source, provide a link to the Creative Commons license, and indicate if changes were made. The images or other third party material in this article are included in the article's Creative Commons license, unless indicated otherwise in a credit line to the material. If material is not included in the article's Creative Commons license and your intended use is not permitted by statutory regulation or exceeds the permitted use, you will need to obtain permission directly from the copyright holder. To view a copy of this license, visit http://creativecommons.org/ licenses/by/4.0/.

(c) The Author(s) 2019 